\title{
Parametric Study of Shear Stress Along Fiber Reinforced Plastic and Concrete Bonded Interface
}

\author{
L. Zhang \\ Yellow River Institute of Hydraulic Research \\ YRCC \\ Zhengzhou ,P.R. China
}

\author{
Y. Yang \\ Yellow River Institute of Hydraulic Research \\ YRCC \\ Zhengzhou, P.R. China
}

\author{
J. Zheng \\ Yellow River Institute of Hydraulic Research \\ YRCC \\ Zhengzhou ,P.R. China
}

\author{
H.H. Xi \\ Yellow River Conservancy Commission of the Ministry of \\ Water Resources \\ Zhengzhou, P.R. China \\ X.L. Kong \\ Nanjing Technical Vocational College \\ Nanjing, P.R. China
}

\begin{abstract}
The characteristics of the fiber reinforced plastic (FRP) and concrete bonded interface directly decided the results of structural reinforcement. The shear test was well simulated, and the shear stress distribution along the bonded interface was obtained by using 2D and 3D finite element method. The parametric study of influential factors (e.g., Young's moduli, shear moduli, and thickness, etc) on shear stress of the FRPconcrete bonded interface was discussed, and the influence of stress concentration on the interfacial shear stress distribution characteristics was gained. The results are very useful for designing the shear-resisting bonding strength test as well as characterizing the FRP-strengthened concrete bonded interface.
\end{abstract}

Keywords-FRP ; concrete ; bonded interface, shear stress, parametric study.

\section{INTRODUCTION}

The bonded surface between fiber reinforced plastic (FRP)plate and concrete is the key part of FRP plate reinforced concrete structure. The failure of reinforced structure is often caused by tiny cracks of bonding surface, and then developed into the larger cracks, eventually led to structure damage as a whole. The stand or fall of interfacial bond properties will play an important role in the success or failure of the reinforced structure. Interfacial bonding strength is divided into the shear bond strength (parallel to the bonding surface) and tensile bond strength of two bonded (perpendicular to the surface), the bonding interface was often in direct shear stress state under some condition of appropriate external load. Therefore, accurate measurement and analysis of adhesive interfacial shear stress distribution was the precondition of FRP plate reinforced concrete structural design

The ASTM D143 and ASTM D905 were respectively used to measure the whole piece of wood and cementing the shear strength of lumber by American Society for Testing Material[1,
2]. These two kinds of test methods were compared by Okkonen [3], the results showed that the shear strength measured by former method was smaller than the latter. It was important to note that shear strength was the ultimate limit of pressure divided by the corresponding shear failure area, which was the average shear strength, it met the assumption of uniform distribution on the interface shear stress. But in fact, the stress along bonding interface was not equally distributed.

Cramer[4]simulated the ASTM D143 block shear test by two-dimensional finite element method, the shear stress concentration factor of the specimens was 2.36. Zhang et al.[5] simulated the bonding interface shear test of reinforced concrete components by FRP plate using 2-d finite element method, the shear stress concentration factor was $4.2 \sim 6.9$. Moses and Prion [6] obtained the shear strength of block shear by using three-dimensional finite element method, the stress concentration factor for gaps at least was equal to 2 .

To sum up, the stress concentration of bonding interface gaps played an important role in measuring the actual shear bond strength, the results showed that it was much difference between the two-dimensional FEM calculation and the threedimensional FEM calculation. Therefore, it was urgent to study the influence of the stress concentration of the block shear specimen to the shear strength of the bonded FRPconcrete interface, the theoretical analysis and numerical simulation methods were adopted, interfacial shear stress distribution was obtained. The results were very useful for designing the shear-resisting bonding strength test as well as characterizing the FRP-strengthened concrete bonded interface.

\section{THE MODELS AND METHODS}

With reference to ASTM D905 shear test method, shear block was improved, the size of the specimens was shown in fig. 1 (a), and the thickness of the FRP plate could be adjusted 
freely. The uniform vertical displacement was applied to simulate test load, as shown in fig. 1 (b).

On the assumption that shear stress of FRP and concrete interface were under the premise of uniform distribution, interfacial shear strength expression was:

$$
\tau_{f-c}=P_{u} / A(1)
$$

where, $\tau_{f-c}$ was for determination of shear strength of FRP and concrete, $P_{u}$ was ultimate load, which was external load value imposed when the shear specimen damage, $A$ was the area of FRP and concrete bonded interface.

The interface shear strength was assumed as $\tau_{f-c}^{\prime}$, bonded interface damage area was assumed as $A$, so the ultimate applied load was:

$$
P_{u}=\tau_{f-c}^{\prime} \cdot A_{(2)}
$$

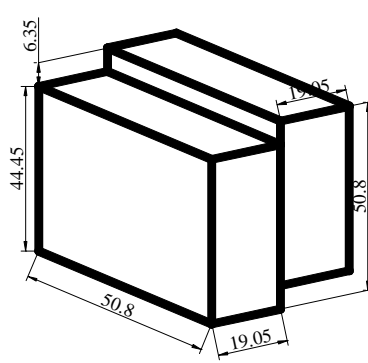

(a) shear specimens

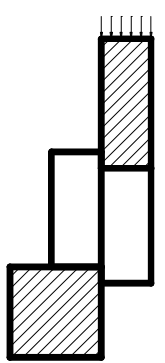

(b)load conditions
FIGURE I. IMPROVED ASTM D905 SHEAR STRENGTH TEST

A certain displacement load was imposed on specimen, the actual load applied on the specimen could be obtained through the finite element analysis, which was resultant force loading on the surface, recorded as $\Sigma P$, the ratio of applied external forces and limit external forces was $\phi$

$$
\phi=\Sigma P / P_{u}=\Sigma P / \tau_{f-c}^{\prime} \cdot A_{(3)}
$$

The stress concentration factor (SCF) was adopted to characterized the relationship between maximum shearing stress and shear strength of FRP and concrete, which was as follow

$$
S C F=\frac{\tau_{\max }}{\tau_{f-c}^{\prime}}=\frac{\tau_{i \max } / \phi}{\tau_{f-c}^{\prime}}=\frac{\tau_{i \max } \cdot A}{\Sigma P}
$$

where, $\tau_{\max }$ was the maximum shearing stress on the bonding interface when the interface shear strength reached ultimate shear strength, and the real SCF value could be obtained, $\tau_{i \max }$ was the maximum stress along FRP-concrete bonding interface calculated by using finite element method.

\section{A. Material Parameter}

There were no consistent conclusions in documents [7, 8]on FRP plate and concrete material property. It was assumed that concrete was isotropic material, and the concrete's compressive strength grade was C25. FRP plate was selected as the carbon fiber reinforced polymer (CFRP), glass fiber reinforced polymer (GFRP) and boron fiber reinforced polymer (BFRP), which were all orthotropic material, and satisfied the conditions of transverse isotropy, which was

$$
\begin{aligned}
& E_{2}=E_{3}, \quad G_{12}=G_{13}, \quad v_{23}=v_{32}, \quad v_{12}=v_{13}, \quad v_{21}=v_{31} \\
& G_{23}=\frac{E_{2}}{2\left(1+v_{23}\right)}
\end{aligned}
$$

\begin{tabular}{|c|c|c|c|c|c|c|c|c|c|}
\hline 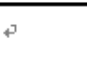 & $\begin{array}{l}E_{1,1} \\
/ G P q_{1}\end{array}$ & $\begin{array}{l}E_{2.1} \\
/ G P Q .1\end{array}$ & $\begin{array}{l}E_{3.1} \\
/ G P a .1\end{array}$ & $v_{1 x}$ & $v_{13}$ & $v_{n}$ & $\begin{array}{l}G_{12.1} \\
/ G P Q\end{array}$ & $\begin{array}{l}G_{13.1} \\
/ G P Q\end{array}$ & $\begin{array}{l}G_{23.1} \\
/ G P Q\end{array}$ \\
\hline Concrete, & 27.579 & 27.579 & 27.579 & 0.2 & 0.2 & 0.2 & 14.496 & 14.4966 & 14.496 \\
\hline$B F R P$ & 2040 & 118.5 & 118.5 & 0.27 & 0.27 & 0.326 & $5.59 \mathrm{~N}$ & $5.59 \mathrm{a}$ & $78.388+a_{1}$ \\
\hline C. & 181 & & 100 & 0.3 & 0.32 & 0.484 & $7.17 \%$ & $7.17 \%$ & 74.021 \\
\hline GFRP & 38.67 & 18.277 & 18.27 & 0.28 & 0.28 & 0.340 & $4.140^{\circ}$ & $4.144^{3}$ & 12.25 \\
\hline
\end{tabular}

The material properties of FRP sheet and concrete were as shown in table 1 .

TABLE I. MATERIAL PROPERTY PARAMETER

Note: $\mathrm{E}_{1}, \mathrm{E}_{2}, \mathrm{E}_{3}-$ Elasticity Modulus; $v_{12}, v_{13}, v_{23}-$ Poisson's ratio; $\mathrm{G}_{12}, \mathrm{G}_{13}, \mathrm{G}_{23}$ - Shear Modulus.

\section{B. The Finite Element Model}

Three-dimensional model was established by finite element software ADINA, it was refined locally for the grid of bonding interface and the load surface, as shown in fig. 2 . In addition to the grid locally refinement, there were $5 \mathrm{~cm}$ and $10 \mathrm{cmmesh}$ grid division respectively in the direction of the specimen thickness (X direction), and $2 \mathrm{~cm}$ and $4 \mathrm{~cm}$ grid mesh division respectively in the specimen length direction $(\mathrm{Z}$ direction) and the width direction (Y direction), as shown in fig. 2 (b).

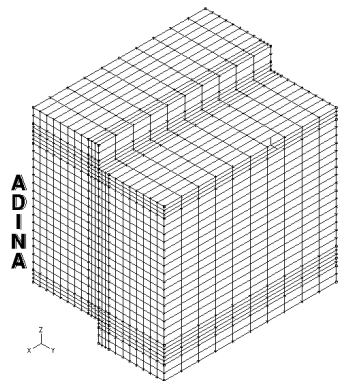

(a)2(Y and $\mathrm{Z})$ to $5(\mathrm{X})$ grid

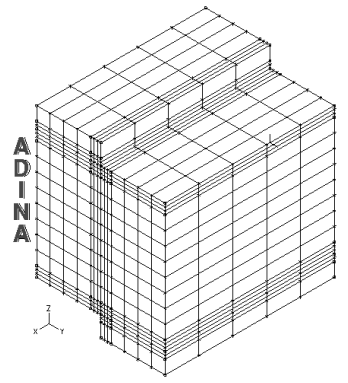

(b)4(Y and Z) to $10(\mathrm{X})$ grid

\section{FIGURE II. FINITE ELEMENT MODEL OF IMPROVED ASTM D905 SHEAR TEST.}

\section{PARAMETRIC ANALYSIS OF SHEAR STRESS}

The shear performance and stress distribution of FRPconcrete bonded interface were affected by elastic modulus, shear modulus and thickness of FRP plate and concrete, which need to be studied further more. For the calculation efficiency and economy, the three-dimensional finite element mesh of 
specimen was that the mesh density was $10 \mathrm{~cm}$ in depth direction, and $2 \mathrm{~cm}$ in width and height direction.

\section{A. The Modulus of Elasticity}

The ratio of FRP elastic modulus $E_{F}$ and concrete elastic modulus $E_{C}$ was adjusted, the corresponded shear stress distribution and SCF along FRP-concrete bonded interface were obtained. Made $\alpha_{(i)}=E_{F(i)} / E_{C(i)}(i=1,2,3)$, the ratio $\alpha$ varied from 1.0 to 10.0 , and $v_{12}, v_{23}, v_{13}, \mathrm{G}_{12}, \mathrm{G}_{13}$ remained unchanged. $G_{23}$ was calculated by equation (6). The shear stress distribution along interface between concrete and FRP plate was chosen, with which the ratio $\alpha$ was equal to 1.0 and 4.0, as shown in fig. 5 .

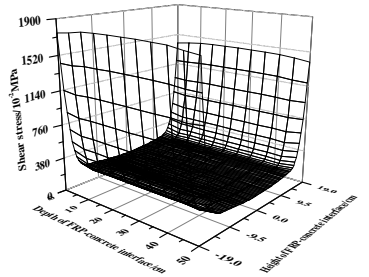

(a) $\alpha=1.0$

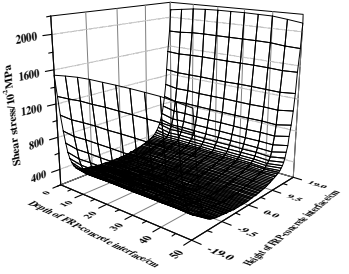

(b) $\alpha=4.0$
FIGURE III. THREE-DIMENSIONAL SHEAR STRESS DISTRIBUTION ALONG FRP-CONCRETE BONDED INTERFACE WHILE ELASTIC MODULUS CHANGE

It can be seen from the fig. 3 , the shear stress at the top of the FRP-concrete bonded interface increased gradually, but gradually became smaller at the bottom, and shear stress change was not obvious in the depth direction.

Fig.4 showed the SCF of FRP and concrete interface with the change of different elastic modulus ratio by twodimensional and three-dimensional finite element calculation. It showed that the calculation results were almost the same, and the two-dimensional plane strain calculation result was more consistent.

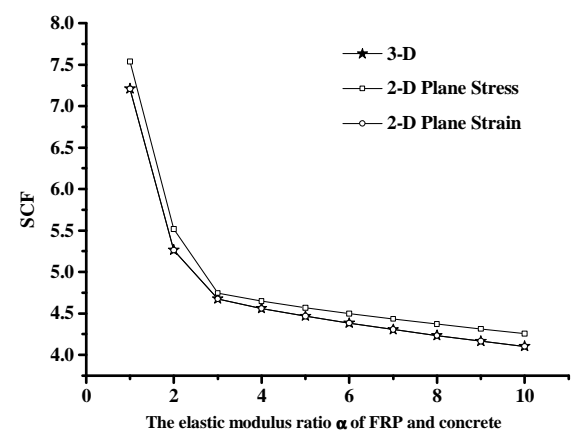

FIGURE IV. EFFECTS OF ELASTIC MODULUS TO SCF OF FRPCONCRETE BONDED INTERFACE

In fig. 3 and fig.4, it can be showed that: (1) The increase of elastic modulus ratio $\alpha$ of FRP and concrete led to the shear stress become larger at the upper and middle of FRP-concrete bonded interface, but the shear stress became smaller at the bottom; (2) When the elastic modulus ratio of FRP and concrete reached a certain value, elastic modulus of FRP contribute to SCF of FRP-concrete bonded interface could be ignored; (3) Shear stress distribution and SCF calculation by three-dimensional finite element method could be simplified as a two-dimensional plane strain problem for analysis.

\section{B. Shear Modulus}

The ratio of FRP shear modulus $G_{F}$ and concrete shear modulus $G_{C}$ was adjusted, made $\chi_{(i)}=G_{F(i)} / G_{C(i)}(i=1,2,3)$, the ratio $\chi_{1}$ varied from 1.0 to 10.0, FRP sheet elastic modulus $E_{F i}(\mathrm{i}=1,2,3)$ and $v_{12}, v_{23}, v_{13}, \mathrm{G}_{12}, \mathrm{G}_{13}$ kept unchanged. $G_{23}$ was calculated by equation (6), and the shear stress distribution along interface between concrete and FRP plate was shown in fig. 5 , which the ratio $\chi_{1}$ was equal to 1.0 and 4.0 .

It can be seen from the fig.5, the stress on the upper and lower of the FRP-concrete bonded interface changed greatly, the stress on the middle was stable, and the shear stress on the upper was always bigger than the bottom's.

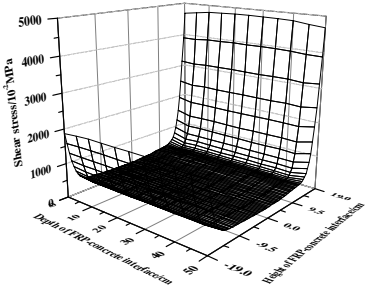

(a) $\chi_{1}=1.0$

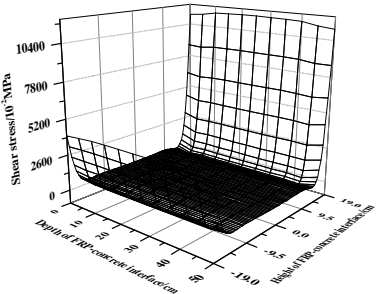

(b) $\chi_{1}=4.0$
FIGURE V. THREE-DIMENSIONAL SHEAR STRESS DISTRIBUTION ALONG FRP-CONCRETE BONDED INTERFACE WHILE SHEAR MODULUS CHANGE

Fig.6 showed the SCF of FRP and concrete interface with the change of different shear modulus ratio by twodimensional and three-dimensional finite element method. It showed that the calculation results were almost same, and the two-dimensional plane strain calculation result was more consistent.

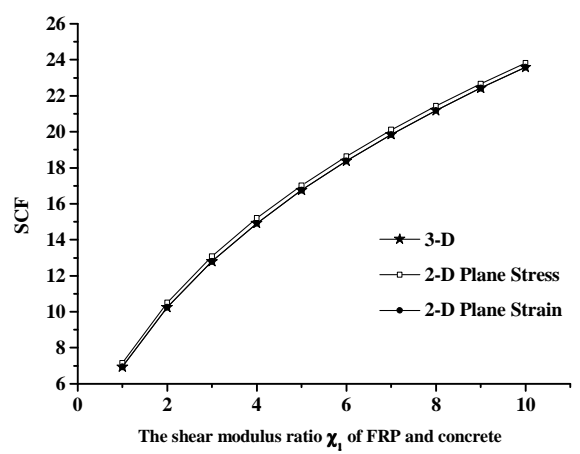

FIGURE VI. EFFECTS OF SHEAR MODULUS TO SCF OF FRPCONCRETE BONDED INTERFACE

In fig.5 and fig.6, it showed that: (1) The increase of shear modulus ratio $\chi_{1}$ of FRP and concrete made the shear stress became larger at the upper and middle of the interface, but the shear stress became smaller at the bottom; (2) When the shear modulus ratio of FRP and concrete reached a certain value, shear modulus of FRP contribute to SCF of FRP-concrete bonded interface was ignored. 


\section{Thickness}

When using FRP sheet for reinforced concrete members, the size of the concrete were also different, therefore, it was need to study the shear stress distribution of the bonding interface between concrete and FRP plate with different size. Material properties of concrete and FRP plate were set to constant, the thickness of FRP was fixed $19 \mathrm{~cm}$ on the left side of the specimens, the thickness of the concrete was changed on the right side of the specimen, respectively $7 \mathrm{~cm}$ and $19 \mathrm{~cm}$. The interfacial shear stress distribution under different thickness of concrete was shown in fig.7. It showed the part shear stress distribution of FRP-concrete bonded interface under different thickness of FRP sheets. Fig. 8 showed the effect of different FRP plate thickness to the SCF.

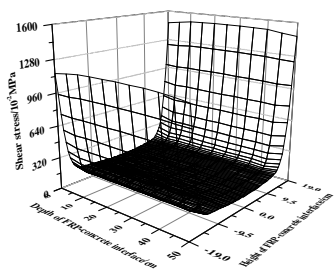

(a) $\beta=19 / 7$

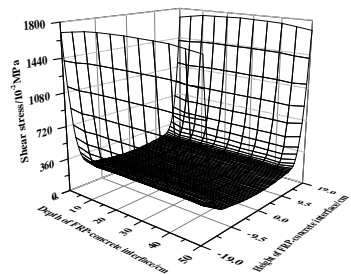

(b) $\beta=19 / 19$
FIGURE VII. THREE-DIMENSIONAL SHEAR STRESS DISTRIBUTION ALONG FRP-CONCRETE BONDED INTERFACE WHILE THICKNESS CHANGE.

It can be learned from fig.7 that stress concentration was very obvious on both ends of the interface, and the stress changed greatly, but the change of shear stress was not obvious in the central of interface.

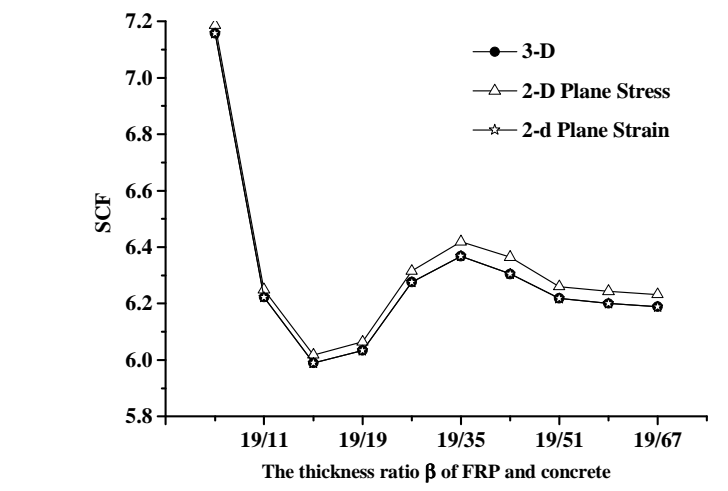

FIGURE VIII. EFFECTS OF THICKNESS TO SCF OF FRPCONCRETE BONDED INTERFACE.

It can be seen from the fig. 8 that the thickness had an important role on the SCF of bonded interface while the thickness of the concrete was close to the thickness of FRP, but finally it tended to steady while the thickness of concrete reach twice the thickness of the FRP.

\section{CONCLUSION}

Based on the shear bond strength of FRP and concrete interface, ASTM standard D905 shear specimens had been improved, bonded interface shear test of FRP reinforced concrete member was simulated by using three-dimensional finite element method, the main conclusions were as follows:
(1) The changes of elastic modulus of concrete and FRP will influence the shear stress on the FRP-concrete interface. The increase of specific value between the FRP and concrete elastic modulus will result in the increase of the shear stress on the upper and middle parts of the interface, and the stress concentration factors then becomes smaller consequently, which will later result in the shear stress on the bottom interface becoming weaker; when specific value of the FRPconcrete elastic modulus increases to a certain value, the increase of FRP elastic modulus may slightly influence the factors of stress concentration on the FRP-concrete interface.

(2) Changes of the concrete-FRP shear modulus can influence greatly the shear stress on the upper and bottom sides of the FRP-concrete interface but influence slightly that in the middle of the interface; when FRP-concrete shear modulus specific value changes, the increase of FRP shear modulus may greatly influence the factors of stress concentration on the FRP-concrete interface.

(3) When the thickness specific value of FRP and concrete differs slightly, they may greatly influence the shear stress strength and the stress concentration factors on the interface; but such influence will become weak when the specific value increases to certain value.

(4) Shear stress distribution and SCF calculation by three-dimensional finite element method can be simplified as a two-dimensional plane strain problem for analysis.

The influence rules of stress concentration to the distribution of shear stress on the interface was discussed mainly, which provides theoretical guidance and instruction to the following-up shear-resisting bonding strength test as well as technical support for the processing of FRP-reinforced concrete bonded interface.

\section{ACKNOWLEDGEMENTS}

This work was financially supported by the National Natural Science Foundation of China (51209102), and fundamental research funds for the central nonprofit research institutions (HKY-JBYW-2013-04).

\section{REFERENCES}

[1] ASTM Standard D143 - 14, Standard methods of Testing Small Clear Specimens of Timber, ASTM International, West Conshohocken, PA, 2014, DOI: 10.1520/D0143, www.astm.org, 2014.

[2] ASTM Standard D905 - 13 , Standard Test Method for Strength Properties of Adhesive Bonds in Shear by Compression Loading, ASTM International, West Conshohocken, PA, 2013, DOI: 10.1520/D0905, www.astm.org, 2013.

[3] Okkonen, E.A. and B.H. River, Factors affecting the strength of blockshear specimens. Forest Products Journal,39(1),pp. 43-50,1989.

[4] Cramer, S.M., Failure modeling of wood structural members, Civil Engineering Department, Colorado State University: Fort Collins, Colorado, 1984.

[5] Zhang L, Wang J, Zhou K, et al. Two-dimensional Shear Stress on Bonding Interface of FRP Plate Reinforced Hydraulic Concrete. Applied Mechanics and Materials, 477-478, pp. 850-857, 2014.

[6] Moses, D.M. and H.G.L. Prion, Stress and failure analysis of wood composites: A new model. Composites Part B: Engineering, 2004. 35(3),pp. 251-261, 2004. 
[7] Saadatmanesh, H. and A.M. Malek, Design guidelines for flexural strengthening of RC beams with FRP plates. Journal of Composites for Construction,2(4),pp. 158-164, 1998.

[8] Barbero, E.J., Introduction to composite materials design. Taylor and Francis: Philadelphia, PA, 1999. 